Section Editor Mitchell S.V. Elkind, MD, MS

Maisha T. Robinson, MD Kevin M. Barrett, MD

Correspondence to Dr. Robinson: mtrobinson@mednet.ucla.edu

\title{
Emerging Subspecialties in Neurology:
} Neuropalliative care

Palliative medicine, as defined by World Health Organization, is the specialty that recognizes and attempts to prevent or alleviate physical, social, psychological, and spiritual suffering. ${ }^{1}$ Understanding the principles of palliative care should be an essential component of neurologic training, as the trajectory of many neurologic illnesses is progressive and incurable. ${ }^{2}$ Given the delicate nature of many of the conversations that neurologists have with patients at the time of diagnosis or during acute illness and hospitalization, expertise in discussing a patient's wishes, handling difficult conversations, and providing adequate symptom-based management is critical. Neurologists are often viewed as consulting physicians; however, patients living with chronic neurologic diseases such as multiple sclerosis, dementia, Parkinson disease, amyotrophic lateral sclerosis (ALS), or sequelae of stroke often consider their neurologist as one of their primary physicians. Therefore, neurologists are positioned in both the outpatient and inpatient care settings not only to address symptoms referable to the disease but also to improve overall quality of life for patients and caregivers and to facilitate end-of-life care.

The intersection of neurology and palliative care. For decades, neurologists have acknowledged the importance of offering quality care to dying patients and the need for improved symptomatic management of patients at the end of life. ${ }^{3}$ Despite this necessity, widespread incorporation of palliative care into neurologic practice has been limited. Lack of knowledge regarding opioid dosing and titration and unease with prescribing analgesics are significant barriers. ${ }^{4}$ In a study assessing pain medicine education among practicing neurologists, $89 \%$ of respondents thought that more pain education was needed in residency training, and $91 \%$ of respondents thought that more pain education was necessary for practicing general neurologists. ${ }^{4}$ A survey of US neurologists' beliefs and attitudes surrounding end-of-life care indicated that there was a lack of general knowledge regarding basic palliative care principles. ${ }^{5}$ The study found that $37 \%$ of respondents thought it was illegal to administer analgesics in doses that risked respiratory depression in terminally ill patients with ALS, and 40\% of respondents thought that legal counsel was needed to consider withdrawal of life-sustaining treatment.

Efforts to address the palliative care knowledge gap among neurologists have emerged through American Academy of Neurology (AAN) educational programs. Since 1971, sessions focused on pain management have been offered at the annual meetings, and since 2007, palliative care courses have been available to attendees. A wide variety of topics have been covered, including methods of improving mobility in patients with ALS, treatment of nonmotor symptoms in patients with Parkinson disease, and end-of-life care. The AAN also established a Pain and Palliative Care Section in 1996 as a forum for those interested in pain as it relates to terminal and end-of-life conditions.

The Accreditation Council for Graduate Medical Education (ACGME) requires that adult neurology residency training include exposure to end-of-life care and palliative care topics, as well as pain management. ${ }^{6} \mathrm{Pal}-$ liative care instruction has been integrated at multiple levels of graduate education. According to a 2009 survey of adult neurology program directors, $52 \%$ of programs provide a didactic on end-of-life and palliative care principles. ${ }^{7}$ Five percent of programs have an internal rotation, and $3 \%$ of programs offer an external rotation in palliative care. ${ }^{7}$ In addition to hospital-based rotations and individual didactics, palliative care courses that are geared toward improving resident knowledge in end-oflife care, prognostication, opioid dosing, communicating with patients and their families, delivering bad news, and holding a family conference have been successfully implemented. This method has demonstrated better postcourse knowledge and confidence in performing these tasks. ${ }^{8}$

Postresidency palliative care training. Opportunities for advanced training in palliative medicine are available to interested neurologists. In 2006, Hospice and Palliative Medicine was recognized by the American Board of Psychiatry and Neurology (ABPN) as a subspecialty with a qualifying examination. According to the ABPN Credentials Department, as of March 2013, 53 neurologists are board-certified in palliative medicine, which represents approximately $0.3 \%$ of the neurology workforce. 
Beginning in 2012, a 12-month fellowship training program by a board-eligible or board-certified allopathic physician is required for board certification in Hospice and Palliative Medicine. According to the American Academy of Hospice and Palliative Medicine, fellowship training programs focus on interdisciplinary teamwork, quality improvement, and research methodology in patients with advanced illness; neuropsychiatric and medical comorbidities in populations with life-threatening diseases; the management of pain and nonpain symptoms; ethical and legal decision-making, communication; psychosocial and spiritual issues; death and dying; bereavement support for the family; and the hospice and palliative approach to care. ${ }^{9}$ Exposure to longterm, hospice, and inpatient care is also a required part of the training. There are 85 fellowship programs, 78 of which are approved by the ACGME.?

In addition to dedicated palliative medicine fellowships, experiential learning may be incorporated into neurology subspecialty postresidency training. Fellowships with patient exposure primarily in the inpatient (i.e., neurohospitalist, neurocritical care) and outpatient (i.e., behavioral neurology, neuromuscular, and movement disorders) setting would benefit from an elective rotation with palliative medicine or hospice. The emergence of simulation centers in academic institutions could be leveraged to develop neurosimulation modules to demonstrate palliative care competency.

Neuropalliative care career opportunities. Although some physicians trained in palliative medicine choose to abandon their primary specialty to concentrate on palliative medicine full-time, most neurologists incorporate the principles into their general or subspecialty practice. ${ }^{10}$ There are opportunities for neurologists to primarily practice palliative care as hospice directors and liaisons, ${ }^{10}$ as fellowship program directors, or as consultants on a palliative medicine service. In the future, neurologists trained in palliative care may assume more specialized roles such as performing consultations in the neuroscience intensive care unit, acting as members of institutional ethics committees, providing interdisciplinary care in ALS clinics, or offering neurologic expertise on the inpatient palliative care service.

The value of incorporating a trained neurologist into the multidisciplinary palliative care team is that neurologists would be able to offer disease-specific knowledge, including the typical trajectory and prognosis of common neurologic diseases, as well as anticipatory guidance to facilitate management of typical symptoms that often arise as the disease progresses. In addition, neurologists are adept at interpreting neurologic signs that may be early indicators of disease progression or distress and may incorporate neuroimaging results into discussions with patient families and care teams to further understanding and acceptance of the terminal nature of the disease process. Neurologists would also aid the team in delivering appropriate end-of-life care for patients with catastrophic intracranial processes and in patients who are approaching brain death.

Common scenarios that illustrate the value of neuropalliative care include massive intracranial hemorrhage or malignant cerebral infarction. Although a poor clinical outcome is likely for many patients, some situations present an uncertain prognosis. In these instances, neurologists have an opportunity to serve a pivotal role in leading the conversation regarding the patient's clinical course. Facilitating discussions with the patient and the family about critical decisions such as whether to withhold or withdraw life-sustaining measures or how long to conduct a timed trial of an intervention may assist the family with making difficult decisions that are aligned with the patient's overall goals of care. Keeping the neurology team involved during these times of uncertainty encourages continuity of care and builds trust with the patient and the family. Palliative care principles such as addressing the psychological issues that may arise as a result of a physical disability, supporting a new caregiver, managing symptoms, offering spiritual care, and providing care planning resources may be incorporated into these interactions to promote a sense of comprehensive care for the patient.

Neurologists trained in palliative care also have an opportunity to teach neurology trainees how to care for patients across the continuum of their diseases, including how and when to shift the focus of care from disease-specific treatment to focus on symptom control and quality of life and how to engage in delicate conversations about end-of-life care and hospice. The hope is that by increasing the number of neurologists with training in palliative care and end-of-life care, a trend will emerge toward improved symptom management, earlier hospice referrals, and decreased aggressive care at the end of life. Having the dual skill sets of neurology and palliative medicine would prove invaluable to patients, families, and the palliative medicine consult teams.

The future of neuropalliative care. The value of neurologists with advanced training in palliative medicine will likely increase in the near future as measuring end-of-life care evolves into a standardized quality metric in parallel with incentives to decrease hospitalizations and length of stay. In addition, continued scrutiny of health care costs at the end of life will undoubtedly encourage physicians, including neurologists, to focus on advance care planning and symptom control during the earlier stages of chronic illness.

Neuropalliative care is a burgeoning subspecialty benefiting from an increasing interest by recent residency graduates. It has the potential to serve a vital 
role in the management of our patients, those with chronic, degenerative, incurable, and end-stage neurologic diseases, as we aim to improve the quality of life for our patients throughout their disease processes while they are living and while they are dying.

\section{AUTHOR CONTRIBUTIONS}

M.T.R.: study concept and design, acquisition of data, analysis and interpretation, critical revision of the manuscript for important intellectual content. K.M.B.: analysis and interpretation, critical revision of the manuscript for important intellectual content, study supervision. All authors read and approved the final manuscript.

\section{STUDY FUNDING}

No targeted funding reported.

\section{DISCLOSURE}

M. Robinson reports no disclosures relevant to the manuscript. K. Barrett receives support from the NINDS for his role in the Stroke Hyperglycemia Insulin Network Effort (SHINE) trial. Go to Neurology.org for full disclosures.

Received November 5, 2013. Accepted in final form February 21, 2014.

\section{REFERENCES}

1. World Health Organization. World Health Organization Definition of Palliative Care. 2013. Available at: http://www.who. int/cancer/palliative/definition/en/. Accessed November 4, 2013.
2. American Academy of Neurology Ethics and Humanities Subcommittee. Palliative care in neurology. Neurology 1996;46:870-872.

3. Foley KM, Carver AC. Palliative care in neurology. Neurol Clin 2001;19:789-799.

4. Galer BS, Keran C, Frisinger M. Pain medicine education among American neurologists: a need for improvement. Neurology 1999;58:1710-1712.

5. Carver AC, Vickrey BG, Bernat JL, Keran C, Ringel SP, Foley KM. End-of-life care: a survey of US neurologists' attitudes, behavior and knowledge. Neurology 1999;53: 284-293.

6. ACGME Requirements for Graduate Medical Education in Neurology. 2010. Available at: http://www.acgme.org/ acgmeweb/Portals/0/PFAssets/ProgramRequirements/180 neurology_07012010.pdf. Accessed November 4, 2013.

7. Schuh LA, Adair JC, Drogan O, Kissela BM, Morgenlander JC, Corboy JR. Education Research: neurology residency training in the new millennium. Neurology 2009; 72:e15.

8. Schuh LA, Biondo A, An A, et al. Neurology resident learning in an end-of-life/palliative care course. J Palliat Med 2007;10:178-181.

9. American Academy of Hospice and Palliative Medicine. 2013. Available at: http://www.aahpm.org. Accessed November 4, 2013.

10. Shaw G. Special report: Bringing palliative care to neurology. Neurol Today 2010;10:16-17. 


\title{
Neurology
}

\author{
Emerging Subspecialties in Neurology: Neuropalliative care \\ Maisha T. Robinson and Kevin M. Barrett \\ Neurology 2014;82;e180-e182 \\ DOI 10.1212/WNL.0000000000000453
}

This information is current as of May 26, 2014

\section{Updated Information \& Services}

\section{References}

Citations

Subspecialty Collections

Permissions \& Licensing

Reprints including high resolution figures, can be found at: http://n.neurology.org/content/82/21/e180.full

This article cites 7 articles, 2 of which you can access for free at: http://n.neurology.org/content/82/21/e180.full\#ref-list-1

This article has been cited by 3 HighWire-hosted articles: http://n.neurology.org/content/82/21/e180.full\#\#otherarticles

This article, along with others on similar topics, appears in the following collection(s):

Palliation pain

http://n.neurology.org/cgi/collection/palliation_pain

Palliative care

http://n.neurology.org/cgi/collection/palliative_care

Information about reproducing this article in parts (figures,tables) or in its entirety can be found online at:

http://www.neurology.org/about/about_the_journal\#permissions

Information about ordering reprints can be found online:

http://n.neurology.org/subscribers/advertise

Neurology ${ }^{\circledR}$ is the official journal of the American Academy of Neurology. Published continuously since 1951, it is now a weekly with 48 issues per year. Copyright @ 2014 American Academy of Neurology. All rights reserved. Print ISSN: 0028-3878. Online ISSN: 1526-632X.

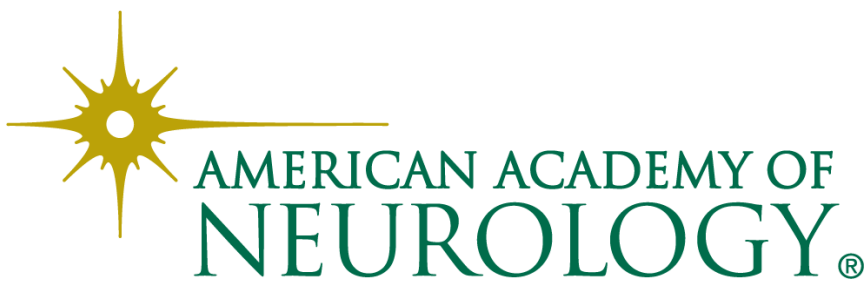

